\title{
Intraabdominal lymphangioma : A Case Report
}

\author{
Lt Col R Handa (Retd)*, Col R Kale ${ }^{+}$, Lt Col MM Harjai", Col V Dutta**
}

MJAFI 2007; 63 : 80-81

Key Words: Lymphangioma; Lump abdomen; Intestinal obstruction

\section{Introduction}

$\mathrm{L}$ ymphangiomas are the commonest tumours of infancy and $75 \%$ occur in the cervical region. $90 \%$ of all lymphangiomas manifest in the initial two years of life. However, intraabdominal lymphangiomas are rare, usually slow growing and manifest in early adulthood [1]. Mesenteric cystic lymphangioma is a rare cause of bowel obstruction and preoperative diagnosis is difficult due to silent clinical course. We present a case of intraabdominal lymphangioma in an infant which presented as a diagnostic dilemma.

\section{Case Report}

A 10 month old male child presented with recurrent episodes of subacute intestinal obstruction. Clinical examination revealed a vague mass in the entire left abdomen. Ultrasound (USG) and computed tomography (CT) reported a multicystic mass. Exploration revealed an extensive multicystic infiltrating mass in the mesentery of the small bowel causing narrowing of the lumen (Fig.1). Extensive resection of the multicystic mass and the part of the engulfed ileum was done.

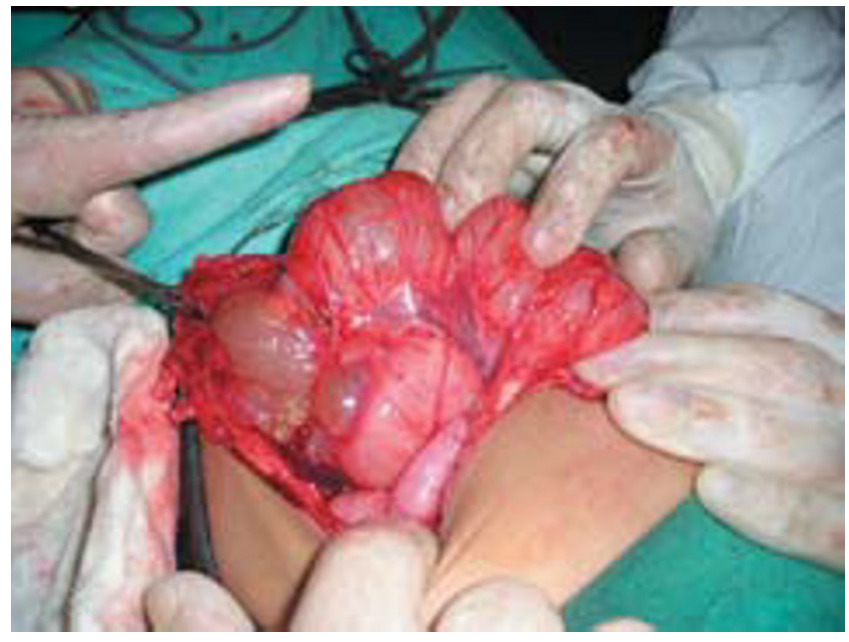

Fig. 1 : Operative photograph showing bunches of lymphangioma in the mesentery of small bowel
Postoperative recovery was uneventful without any lymphatic discharge. Histopathology confirmed lymphangioma showing multiple cystic spaces lined by flat low lying epithelium with surrounding tissue of scattered lymphoid cells (Fig. 2). One year follow up with USG abdomen has shown no recurrence.

\section{Discussion}

Intraabdominal cystic lymphangioma of the mesentery is a rare congenital lesion with a relatively low growth potential. It is typically found in young adults and presents with chronic features. In younger children, the lymphatic malformations are aggressive [2]. Lymphangiomas are prone to recurrence and infiltrating growth. These benign lesions usually present as painless abdominal distension or with complications like volvulus, infection, intracystic hemorrhage and intestinal obstruction. The preoperative diagnosis is difficult, without a high index of suspicion. Most of the cases can be diagnosed USG abdomen [3]. In some cases confirmation of diagnosis may require additional investigations like $\mathrm{CT}$ or magnetic resonance

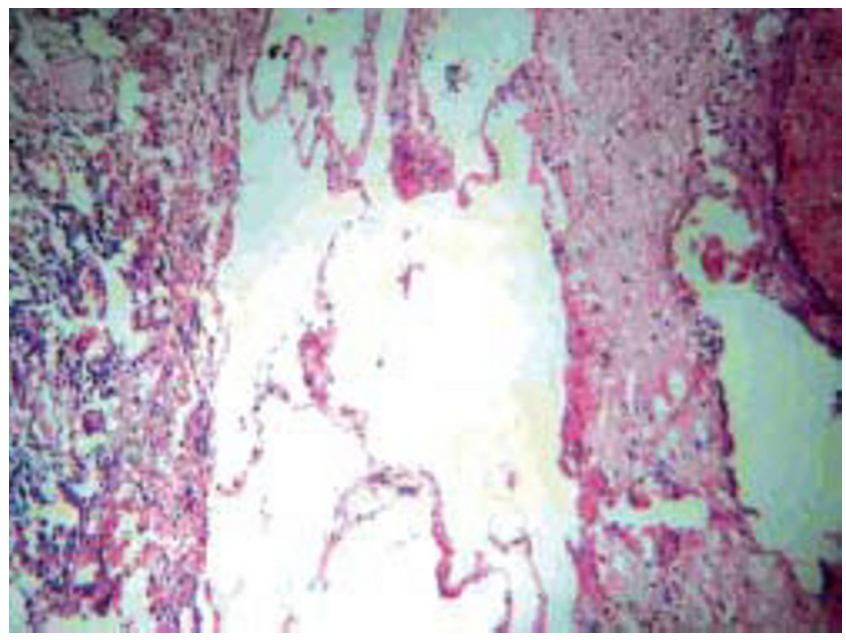

Fig. 2: Histopathology shows multiple cystic spaces lined by flat low lying epithelium with surrounding scattered lymphoid cells ( H\&E stain, $x$ 200)

"Ex-Classified Specialist (Surgery and Paediatric Surgery), Command Hospital (EC), Kolkata - 700027.+Senior Advisor (Surgery and Paediatric Surgery), "Classified Specialist (Surgery and Paediatric Surgery), ${ }^{* *}$ Senior Advisor (Pathology \& Oncopathology), Army Hospital (Research and Referral), New Delhi-110010.

Received : 17.12.2004; Accepted : 19.05.2005 
imaging (MRI) [4,5]. Many authors are of the opinion that a final diagnosis can only be established by histopathological examination [4].

Cystic lymphangioma can be enucleated completely without compromising the bowel vascularity. However, in cases of infilterative lymphangioma, resection of the involved part of the mesentry along with the bowel is recommended. A common postoperative complication is persistent lymphatic leak with or without infection. Other modalities of treatment for unresectable intraabdominal lymphangiomas include sclerotherapy with doxycycline or alcohol $[6,7]$. We recommend that abdominal USG complemented by CT scan allows the hypothesis of lymphangioma, but histological examination will confirm the diagnosis.

\section{Conflicts of Interest}

None identified

\section{References}

1. Fernandez HI, Bregante J, Mulet FJF, Moron CJM. Abdominal cystic lymphangioma. Cir Pediatr 1998; 11:171-3.

2. De Perrot M, Rostan O, Morel P, Le Coultre C. Abdominal lymphangioma in adults and children. Br J Surg 1998; 85: 3957.

3. Merrot T, Chaumoitre K, Simeoni-Alias J, et al. Abdominal cystic lymphangiomas in children. Clinical, diagnostic and therapeutic aspects: apropos of 21 cases. Ann Chir 1999; 53: 494-9.

4. Kably A, Moumen M, Raissouni N, et al. Cystic lymphangiomas of the mesentery and the epiploon. About two cases. Gynecol Obstet Fertil 2003; 31:136-8.

5. Huis M, Balija M, Lez C, Szerda F, Stulhofer M. Mesenteric cysts. Acta Med Croatica 2002; 56: 119-24.

6. Mabrut JY, Grandjean JP, Henry L, et al. Mesenteric and mesocolic cystic lymphangiomas. Diagnostic and therapeutic management. Ann Chir 2002; 127: 343-9.

7. Stein M, Hsu RK, Schneider PD, et al. Alcohol ablation of a mesenteric lymphangioma. J Vasc Interv Radiol 2000; 11: 247 50 .

\section{ANNOUNCEMENT BEST REFEREE AWARD : MJAFI}

The Best Referee Award has been instituted with effect from 2006 to appreciate the contribution made by the referees in publication of the articles in MJAFI. The award will be given during the AFMRC annually. The criteria for selection of Best Referee would be:
(a) Usage of email in all correspondence
(b) First response within two weeks of receipt of article
(c) Subsequent responses within one week
(d) Most constructive comments 